\section{Potential utility of double-balloon enteroscopy for the diagnosis and evaluation of gastrointestinally mediated allergy}

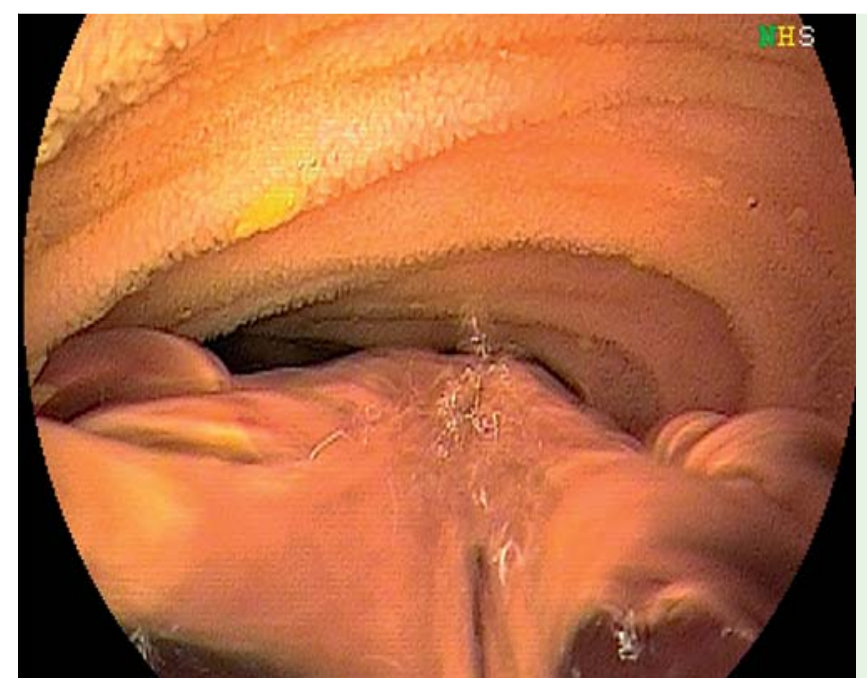

Fig. 1 Immersion endoscopy showing normal villi within the deep ileum, which therefore excluded a diagnosis of celiac disease.

A 41-year-old man was admitted because of postprandial abdominal pain, diarrhea, headache, and reduced physical activity. After extensive investigations to clarify the differential diagnosis, all of which produced unremarkable findings, rectal double-balloon enteroscopy (rDBE) was performed with the newly available doubleballon enteroscope EN 580-T (FujiFilm Europe, Düsseldorf, Germany). The procedure was performed with carbon dioxide insufflation, reaching a level of $160 \mathrm{~cm}$ above the ileocecal valve without causing significant pain.

No tumor, stenosis, or erosive lesions were seen but, with the improved optical images from the EN 580-T, several nonerosive inflammatory signs were visualiz- ed. Because the patient was known to have intolerance of certain foods, endoscopy-guided segmental lavage was performed to search for local immune phenomena, inducing hyperplasia of lymphoid follicles [1-3]. Therefore, the enteroscope balloon at the tip of the EN 580-T was blocked and $50 \mathrm{~mL}$ saline was delivered into the ileum proximally to the enteroscope. After 1 minute of incubation, the fluid was easily recovered through the 3.2-mm working channel of the enteroscope for later analysis.

Immersion endoscopy during endoscopic lavage showed normal villi within the ileum, thereby excluding celiac disease ( Fig. 1). Marked areas of right-sided colonic erythema and pronounced hyper- plasia of lymphoid follicles were detected along the lower gastrointestinal tract. Increased numbers of lymphoid follicles were detected ( $\geq 10-15 /$ high-powered field [HPF]; normal $\leq 8$ ) [1] using the high-resolution CCD (charge-coupled device) chip and FICE (Fuji intelligent color enhancement) ( Fig.2a,b), and were clearly shown by chromoendoscopy with methylene blue ( $\bullet$ Fig. 2 c), a finding that was subsequently confirmed by histological examination ( Fig.3). The close focus function and zoom endoscopy were able to further demonstrate that the lymphoid tissue was located under an intact epithelial barrier ( Fig.4).

Analysis of the lavage fluid (results are given per mg of protein) revealed increased production of immunoglobulin $\mathrm{E}$ ( $\mathrm{IgE}$ ) locally in the gut $(4.2 \mathrm{U}$, normal $<0.35[2$, 3]) and increased eosinophilic cationic protein levels $(18.8 \mu \mathrm{g}$, normal <4.5). Histologic examination was able to rule out infection, mastocytosis, and eosinophilic gastroenteritis, but showed increased numbers of mast cells $\left(1066 / \mathrm{mm}^{2}\right.$, normal $<600)$ and eosinophils $\left(876 / \mathrm{mm}^{2}\right.$, normal $<200$ ). The diagnosis of gastrointestinally mediated allergy was therefore confirmed and the patient was treated successfully with budesonide, mast cell stabilizers, and antihistamines.

It has been reported that allergic and immuno-inflammatory disorders are increasing along with irritable bowel syndrome [4]. In this report we have highlighted several functions of this new double-balloon enteroscope (the close focus and zoom functions and the 3.2-mm forceps channel) that can be used along with endoscopic lavage to ensure that such diseases are adequately recognized in the near future.
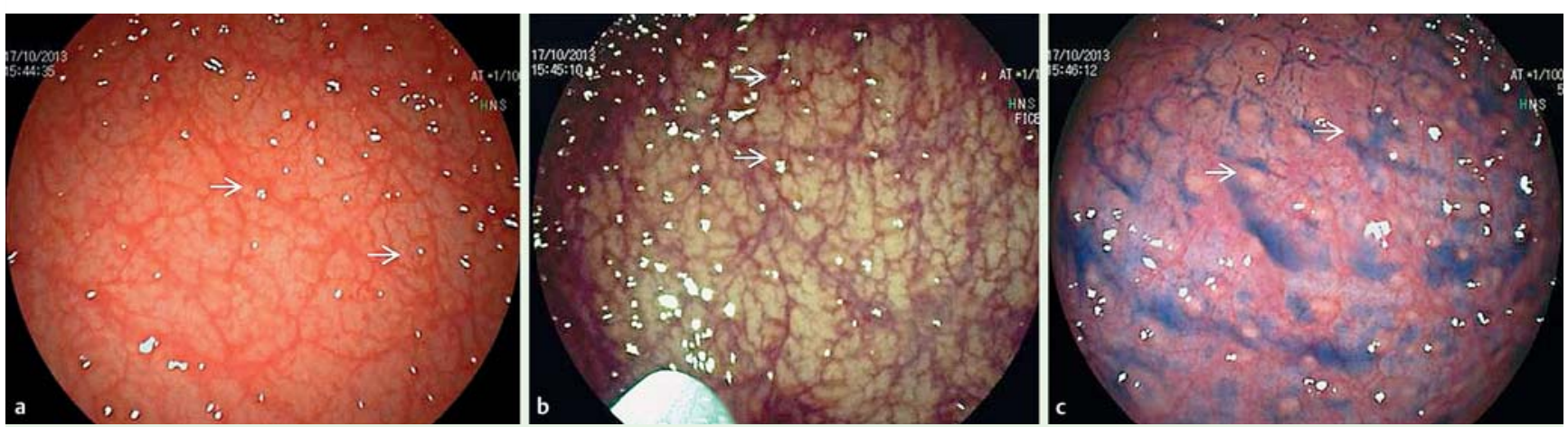

Fig.2 Rectal double-balloon enteroscopy (rDBE) with the high-resolution CCD (charge-coupled device) chip and FICE (Fuji intelligent color enhancement) showing: a, b an erythematous area of the bowel with markedly increased reddish superficial vessels and an increased number of lymphoid follicles (white arrows); $\boldsymbol{c}$ the appearance on chromoendoscopy with methylene blue. 


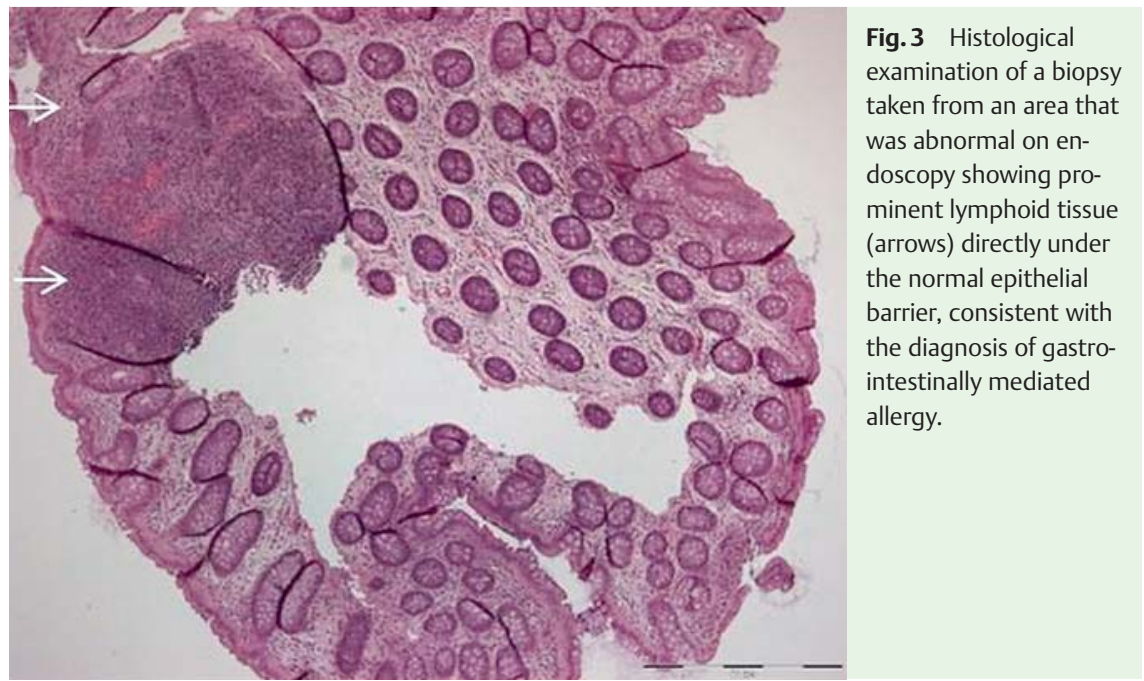

Endoscopy_UCTN_Code_CCL_1AC_2AH

Competing interests: None

\section{Martin Raithel' ${ }^{1}$, Heinz Albrecht ${ }^{1}$, Ralf Rieker ${ }^{2}$, Alexander Hagel ${ }^{1}$, Markus F. Neurath ${ }^{1}$}

${ }^{1}$ Department of Medicine 1, Gastroenterology, Interventional Endoscopy, University of Erlangen-Nuremberg, Germany

2 Department of Pathology, University of Erlangen-Nuremberg, Germany

\section{References}

1 Krauss E, Konturek P, Maiss J et al. Clinical significance of lymphoid hyperplasia of the lower gastrointestinal tract. Endoscopy 2010; 42: 334-337

2 Raithel M, Hahn EG. [Functional diagnostic tests for objectification of gastrointestinally mediated allergies]. Allergologie 1998; 21: 51-64

3 Schwab D, Raithel M, Klein P et al. Immunoglobulin $\mathrm{E}$ and eosinophilic cationic protein in segmental lavage fluid of the small and large bowel identifies patients with food allergy. Am J Gastroenterol 2001; 96: 508 514

4 Vivinus-Nebot $M$, Dainese R, Anty $R$ et al. Combination of allergy factors can worsen diarrheic irritable bowel syndrome: role of barrier defects and mast cells. Am J Gastroenterol 2012; 107: 75-81

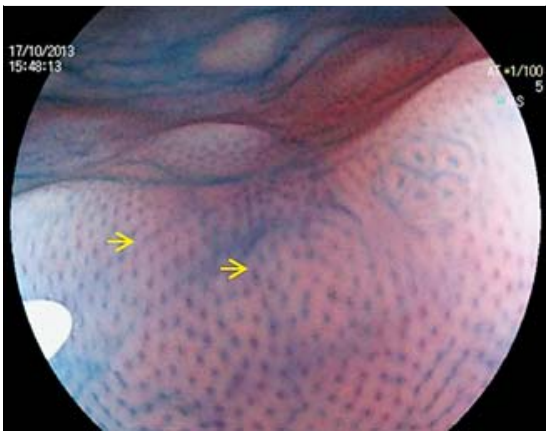

Fig. 4 Rectal double-balloon enteroscopy (rDBE) using the close focus function and zoom endoscopy showing normal, regular crypts of Lieberkuhn in the colon (yellow arrows), which therefore excluded any erosive lesions

Bibliography

Dol http://dx.doi.org/ 10.1055/s-0034-1365440

Endoscopy 2014; 46: E266-E267

(c) Georg Thieme Verlag KG

Stuttgart · New York

ISSN 0013-726X

\section{Corresponding author}

\section{Martin Raithel, MD}

Department of Medicine 1

University of Erlangen-Nuremberg

Ulmenweg 18

91054 Erlangen

Germany

martin.raithel@uk-erlangen.de 